\title{
Rational design of cyclopropane-based chiral PHOX ligands for intermolecular asymmetric Heck reaction
}

\author{
Marina Rubina ${ }^{1}$, William M. Sherrill ${ }^{1}$, Alexey Yu. Barkov² \\ and Michael Rubin*1
}

Open Access

\author{
Full Research Paper \\ Address: \\ ${ }^{1}$ Department of Chemistry, University of Kansas, 1251 Wescoe Hall \\ Drive, Lawrence, KS 66045-7582, USA and ${ }^{2}$ Department of \\ Chemistry, Ural Federal University, pr. Lenina 51, 620000 \\ Ekaterinburg, Russian Federation \\ Email: \\ Michael Rubin* - mrubin@ku.edu \\ * Corresponding author \\ Keywords: \\ asymmetric catalysis; chiral phosphine ligands; cyclopropane; Heck \\ reaction; organophosphorus; transition metal catalysis
}

Beilstein J. Org. Chem. 2014, 10, 1536-1548.

doi:10.3762/bjoc. 10.158

Received: 19 February 2014

Accepted: 03 June 2014

Published: 07 July 2014

This article is part of the Thematic Series "Organophosphorus chemistry".

Guest Editor: P. R. Hanson

(c) 2014 Rubina et al; licensee Beilstein-Institut.

License and terms: see end of document.

\begin{abstract}
A novel class of chiral phosphanyl-oxazoline (PHOX) ligands with a conformationally rigid cyclopropyl backbone was synthesized and tested in the intermolecular asymmetric Heck reaction. Mechanistic modelling and crystallographic studies were used to predict the optimal ligand structure and helped to design a very efficient and highly selective catalytic system. Employment of the optimized ligands in the asymmetric arylation of cyclic olefins allowed for achieving high enantioselectivities and significantly suppressing product isomerization. Factors affecting the selectivity and the rate of the isomerization were identified. It was shown that the nature of this isomerization is different from that demonstrated previously using chiral diphosphine ligands.
\end{abstract}

\section{Introduction}

The asymmetric Heck reaction is one of the most powerful and versatile processes for the enantioselective construction of new carbon-carbon bonds. Intramolecular versions of this reaction catalysed by palladium complexes with BINAP and related diphosphine ligands [1,2] allow for efficient installation of tertiary and quaternary chiral centres leading to a rapid increase of molecular complexity [3-5]. To date, various modes of this transformation are being successfully employed in the synthesis of complex organic molecules [6-14].
Considerable achievements have also been made towards the application of BINAP-type ligands in the intermolecular asymmetric Heck reaction [15]. This reaction was pioneered by Hayashi [16], who demonstrated the arylation of dihydrofuran (1) with phenyl triflate (2a) (Scheme 1) in the presence of $(R)$ BINAP [16-18] produced isomeric dihydrofurans $\mathbf{3 a}$ and $\mathbf{4 a}$, with the latter being the major product, due to substantial isomerization of the double bond. Depending on the reaction conditions, moderate to good selectivities toward formation of 


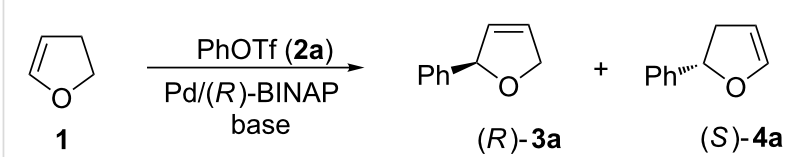

Scheme 1: Intermolecular asymmetric Heck reaction by Hayashi [16].

4a were observed. Remarkably, the obtained products, "normal" 3a and "isomerized" 4a, had the opposite absolute configurations of the stereogenic center at $\mathrm{C} 2$. Moreover, it was found that the enantioselectivity improved during the reaction course. The mechanistic rationale proposed by Hayashi [16] fully accounts for the observed stereoselectivity change (Scheme 2). The catalytic cycle begins with the oxidative addition of $\operatorname{Pd}(0)$ species $\mathbf{5}$ into the aryl triflate $\mathbf{2}$ resulting in the formation of cationic complex $\mathbf{6}$. The latter can coordinate to either of the prochiral faces of dihydrofuran (1) affording diastereomeric $\eta^{2}$-complexes 7 and 10. Subsequent carbopalladation, followed by $\beta$-hydride elimination, produces species 9 and 12, respectively. It was proposed that the diastereomeric complex $\mathbf{1 2}$ has a higher propensity toward further hydropalladation than $\mathbf{9}$. Accordingly, the latter species releases the $(S)$-enantiomer of 2,5-dihydrofuran 3 (path I), while the former undergoes a series of reversible hydropalladations and $\beta$-hydride eliminations, resulting in the formation of a thermodynamically more favoured $\eta^{2}$-complex 14 , which ultimately produces the $(R)$ enantiomer of the isomeric product 4 .
Later, a number of research groups pursued the design of alternative diphosphine ligands to achieve better regio- and enantioselectivity in the intramolecular Heck reaction. Several derivatives of BINAP [19,20] and other chiral diphosphines [21-27] including TMBTP [28-31], BIPHEP [32-34], BITIANP [30,35] (Figure 1) were tested, some of which provided improved selectivity. Nevertheless, in all cases predominant or exclusive formation of the isomerized product 4 was observed.<smiles>[R]Oc1ccc(OC)c(-c2c(OC)ccc(OC)c2-c2ccccc2)c1-c1ccccc1</smiles>

BIPHEP<smiles>Cc1sc(C)c(-c2c(C)sc(C)c2-c2ccccc2)c1-c1ccccc1</smiles>

TMBTP<smiles></smiles>

BITIANP
Figure 1: Chiral diphosphine ligands used for intermolecular asymmetric Heck reaction.

At the same time, several mixed hetereoatom ligands of the $\mathrm{P}-\mathrm{S}$ [36,37], P-O [38], and N-N [39,40] type have also been explored in the intermolecular Heck arylation; however, they demonstrated in most cases only marginal regio- and enantioselectivities. On the other hand, superior results were obtained

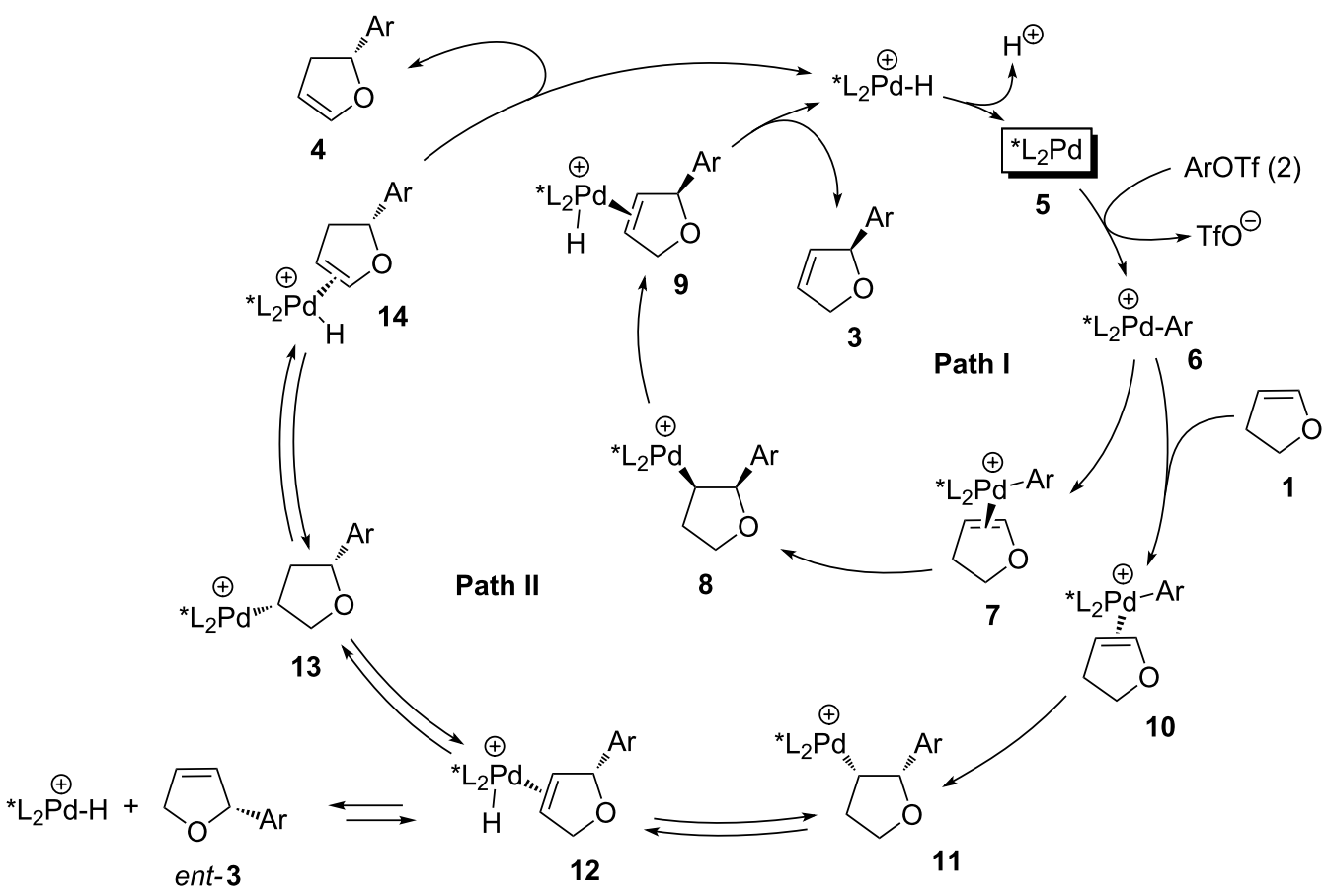


using chiral ligands of the P,N-type [15,41-44]. Particularly, excellent enantioselectivities were achieved using different variations of phosphanyl-oxazoline (PHOX) ligands [45-52], originally introduced by Pfaltz (Figure 2) [53,54]. The remarkable, yet not fully understood feature of PHOX ligands is their low tendency to promote $\mathrm{C}=\mathrm{C}$-bond isomerization [45-52]. Thus, in contrast to the diphosphines, PHOX ligands produced dihydrofuran 3 with very high selectivity. Structural modification of the flat ortho-phenylene tether in the Pfaltz ligand through the incorporation of additional chirality elements into the ligand backbone allowed for significant improvement of the enantioselectivity. Thus, ferrocene-based ligands introduced by Dai and Hou [55,56], and Guiry [57,58] (Figure 2) were employed in the asymmetric Heck reaction of different cyclic olefins. Furthermore, Gilbertson demonstrated PHOX ligands featuring apobornene backbone (Figure 2) exhibit outstanding activities and selectivities in the arylation and alkenylation of different cyclic substrates [59]. A highly efficient asymmetric arylation in the presence of sugar-derived phosphite-oxazoline ligands was reported by Diéguez and Pàmies [47,48].

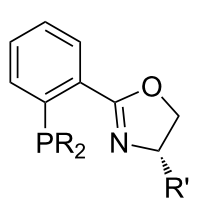

Pfaltz ligands

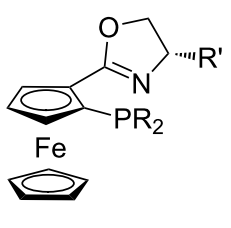

Ferrocene-based ligands

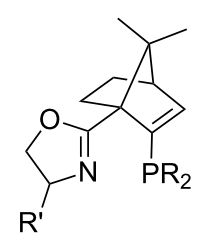

Gilbertson ligands
Figure 2: Chiral phosphanyl-oxazoline (PHOX) ligands used for intermolecular asymmetric Heck reaction.
PHOX ligands are very appealing due to their high catalytic potential and modular design, which permits easy preparation of a series of analogues via the same synthetic route. To date, however, general approach to the ligand design has been largely empirical due to a poor understanding of the factors affecting the activity of the corresponding catalytic systems and the operating modes of asymmetric induction imparted by the employed chiral ligands. In our investigation, we decided to benefit from a well-established strategy commonly used in medicinal chemistry. According to this approach conformationally constrained cyclic analogues of biologically active molecules are employed for elucidation of important mechanisms and identifying critical enzyme binding sites. Analogously, we anticipated that incorporation of a three-membered cycle in the ligand structure [60-63] would impart rigidity to the ligand backbone and provide conformationally constrained systems with amplified steric effects, which can be easily modelled and predicted. This, in turn, could be used to rationally design the ligand structure en route to more efficient catalytic systems. In 2008 we communicated the design and synthesis of a novel series of PHOX ligands featuring a chiral cyclopropyl backbone, as well as their employment in the enantioselective intermolecular Heck arylation reaction [64]. Herein we describe the full account on this investigation, including the results of the structure-activity studies and provide our insight into the origins of the enantioselectivity of this transformation and factors controlling the rate of isomerization reaction.

\section{Results and Discussion}

Our approach to the PHOX ligands with a chiral cyclopropyl backbone is presented in Scheme 3. The synthesis began from optically active 1-methyl-2,2-dibromocyclopropanecarboxylic acid (15) [65] readily available in both enantiomeric forms. The $S$-enantiomer of acid 15 was converted into acyl chloride $(S)$ -

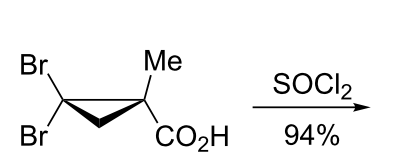

(S)-15

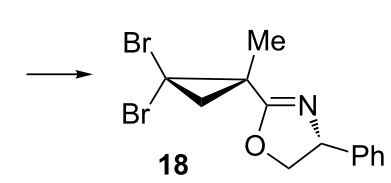

$88 \%$ over two steps

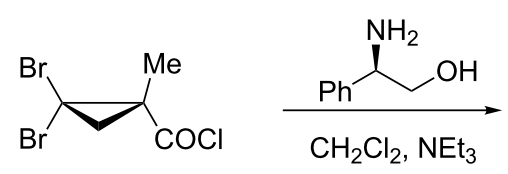

(S)-16
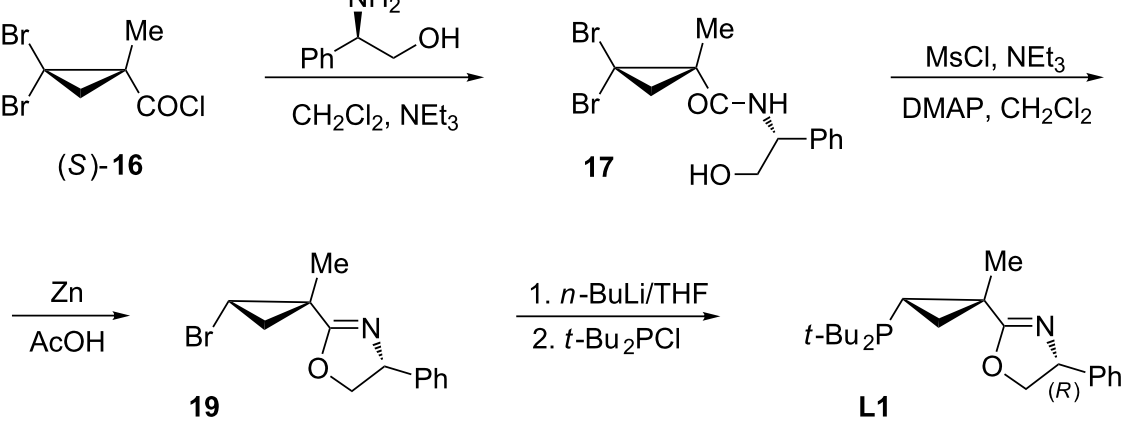<smiles>CC12COC[C@H](c3ccccc3)N=C1CC(Br)C2</smiles>

(dr 4:1)

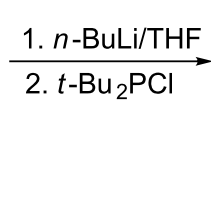<smiles>CCCCCCCC(C)(CCPCCCCC)C1=NC(c2ccccc2)CO1</smiles>

$43 \%$ 
16. Subsequent acylation of $(R)$-phenylglycinol with $(S)$-16 afforded amide 17 , which was subjected to cyclization in the presence of mesyl chloride and a base providing dihydrooxazole 18. Diastereoselective partial reduction of the dibromocyclopropane moiety with zinc dust in glacial acetic acid produced a 1:4 mixture of trans- and cis-bromocyclopropanes 19, which were separated by column chromatography. Lithium to halogen exchange followed by trapping of the resulting cyclopropyllithium species with chlorophosphine produced ligand L1 (Scheme 3).

Ligand $\mathbf{L} \mathbf{1}$ once obtained, was tested in the asymmetric arylation reaction of 2,3-dihydrofuran under various reaction conditions (Table 1). It was found that the reaction proceeded efficiently, yet with only moderate enantioselectivity, in the presence of palladium acetate and Hünig's base (Table 1, entry 3 ). Interestingly, the employment of proton sponge as a base resulted in significant isomerization of product $\mathbf{3 a}$ into the more thermodynamically stable dihydrofurans $4 \mathbf{a}$ and 20a. Close monitoring of the reaction by chiral GC revealed, that the initially formation of "normal" product 3a is observed (Table 1, entry 4); however, by the time when starting material 1 was completely consumed, the entire amount of $\mathbf{3 a}$ produced was transformed into 4a (Table 1, entry 5). Remarkably, the absolute configuration at $\mathrm{C} 2$ did not change at all through the reaction course; moreover, the optical purity of both products 3a and 4a remained constant (Table 1, entries 4 and 5). This feature makes this isomerization mechanistically distinct from the one reported by Hayashi (vide supra).

To better understand the factors affecting the selectivity and efficiency of the asymmetric arylation, we have prepared two more analogues of L1: ligand L2, possessing a diphenylphosphanyl group and ligand $\mathbf{L 3}$ derived from tert-leucinol (Figure 3). Not surprisingly, installation of the less hindered phosphorus moiety in $\mathbf{L} 2$ negatively affected the asymmetric induction: the corresponding product $\mathbf{3 a}$ was obtained in only $78-79 \%$ ee (Table 2, entries 3 and 4). However, in contrast to L1 (Table 2, entries 1 and 2) the selectivity toward 3a in the reaction using $\mathbf{L} 2$ remained high, regardless of the base used.

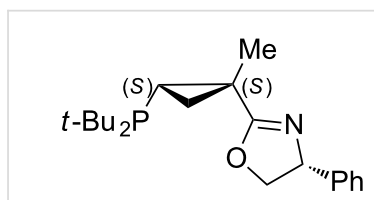

L1

L3

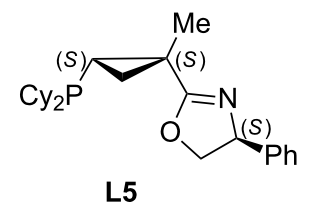

L5<smiles>C[C@H](C[Pb]C(C)(C)C)C1=N[C@@H](C(C)(C)C)CO1</smiles>

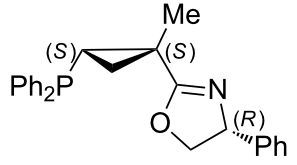

L2

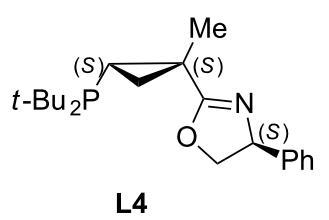<smiles>CC(P)CC(CC(C)C1=NC(c2ccccc2)CO1)C(C)C</smiles>

L6
Figure 3: PHOX ligands with chiral cyclopropyl backbone employed in this study.

Modification of the dihydrooxazole moiety by installation of a bulky tert-butyl group was pursued in attempt to improve the enantioinduction of our catalytic system. Indeed, a number of previously reported PHOX ligands derived from tert-leucinol were shown to provide superior enantioselectivities compared to their analogues obtained from less bulky amino alcohols $[54,57,59]$. However, the arylation carried out in the presence of

Table 1: Selected results on optimization of the reaction conditions for asymmetric Heck arylation using L1.

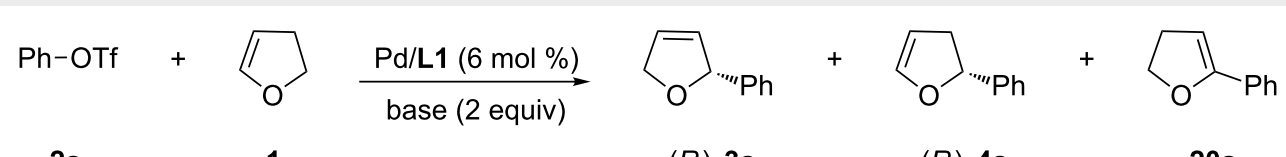

$2 a$

1
$(R)-3 a$
$(R)-4 a$
$20 \mathrm{a}$

\begin{tabular}{|c|c|c|c|c|c|c|c|}
\hline Entry & Pd cat. & Base & Solvent & Time/Temp & $3 a: 4 a$ & ee, $\% a$ & conv, $\%^{b}$ \\
\hline 1 & $\mathrm{Pd}_{2} \mathrm{dba}_{3} \cdot \mathrm{CHCl}_{3}$ & $\mathrm{EtN}(\mathrm{iPr})_{2}$ & benzene & $3 \mathrm{~d} / 70{ }^{\circ} \mathrm{C}$ & 19:1 & 90 & 15 \\
\hline 2 & $\mathrm{Pd}_{2} \mathrm{dba}_{3} \cdot \mathrm{CHCl}_{3}$ & $\mathrm{EtN}(\mathrm{iPr})_{2}$ & THF & $20 \mathrm{~h} / 85^{\circ} \mathrm{C}$ & $10: 1$ & 85 & 60 \\
\hline 3 & $\mathrm{Pd}(\mathrm{OAc})_{2}$ & $\mathrm{EtN}(\mathrm{iPr})_{2}$ & THF & $20 \mathrm{~h} / 85^{\circ} \mathrm{C}$ & 11:1 & 83 & 99 \\
\hline 4 & $\mathrm{Pd}(\mathrm{OAc})_{2}$ & proton sponge & THF & $20 \mathrm{~h} / 60^{\circ} \mathrm{C}$ & $10: 1$ & 88 & 45 \\
\hline 5 & $\mathrm{Pd}(\mathrm{OAc})_{2}$ & proton sponge & THF & $70 \mathrm{~h} / 60{ }^{\circ} \mathrm{C}$ & $>1: 50^{C}$ & 85 & 99 \\
\hline 6 & $\mathrm{Pd}(\mathrm{OAc})_{2}$ & proton sponge & THF & $20 \mathrm{~h} / 90^{\circ} \mathrm{C}$ & $>1: 50^{c}$ & 82 & 99 \\
\hline
\end{tabular}

aEe's of major regioisomers are listed. ${ }^{b}$ Conversion by GC. ${ }^{c}$ Formation of small amounts of dihydrofuran 20 a was observed. 
Table 2: Screening of L1-L3 in the asymmetric Heck arylation of dihydrofuran 1.

\begin{tabular}{|c|c|c|c|c|c|}
\hline & $\begin{array}{l}\text { Dh-OTf } \\
2 a\end{array}$ & $\begin{array}{r}\mathrm{Pd}(\mathrm{OAc}) \\
\text { base } \\
\mathrm{TH}\end{array}$ & $\begin{array}{l}\underset{{ }^{\circ} \mathrm{C}}{\stackrel{\mathrm{mol} \%)}{\longrightarrow}} \\
\text { guiv) }\end{array}$ & $(R)-\mathbf{3 a}$ & $(R)-4 \mathrm{a}$ \\
\hline Entry & Ligand & Base & $3 a: 4 a$ & ee, $\%^{a}$ & conv, $\%^{\mathrm{b}}$ \\
\hline 1 & $\mathbf{L 1}^{\mathrm{c}}$ & $\mathrm{EtN}(\mathrm{iPr})_{2}$ & $11: 1$ & 83 & 99 \\
\hline 2 & $\mathbf{L 1}^{\mathrm{c}}$ & proton sponge & $>1: 50$ & 82 & 99 \\
\hline 3 & L2 & $\mathrm{EtN}(\mathrm{iPr})_{2}$ & $20: 1$ & 79 & 99 \\
\hline 4 & L2 & proton sponge & $15: 1$ & 78 & 99 \\
\hline 5 & L3 & $\mathrm{EtN}(\mathrm{iPr})_{2}$ & $7: 1$ & 87 & 35 \\
\hline 6 & L3 & proton sponge & $1.4: 1$ & $84^{d}$ & 80 \\
\hline
\end{tabular}

${ }^{a}$ Enantioselectivity of a major product. ${ }^{b}$ Conversions by GC. ${ }^{\mathrm{c}}$ Results from Table $1 .{ }^{\mathrm{d}}$ Enantioselectivity of product $(R)-4 \mathrm{a}$ was $80 \%$.

L3 proceeded much more sluggishly (Table 2, entries 5 and 6), and allowed for only insignificant improvement in enantioselectivity ( $84-87 \%$ ee). Most remarkably, the same $(R)$-enantiomer of product 3 was obtained, despite the opposite absolute configuration of $\mathbf{L} \mathbf{3}$ with respect to $\mathbf{L} 1$ (Figure 3). In other words, switching from $\mathrm{Ph}$ to $t$-Bu substituent in the dihydrooxazole ring of the ligand resulted in a reversal of enantioselectivity.

Such an unexpected change in the catalyst selectivity motivated us to perform structural analysis of the key intermediate complexes invoked in the catalytic cycle of the Heck arylation. First, we assessed the possibility of conformational equilibrium for the six-membered arylpalladium species bearing $\mathbf{L} 1$ (Scheme 4). The non-planar six-membered palladacycle [66-69] can potentially adopt one of two conformations: I1, in which the syn-tert-butyl substituent at phosphorus assumes a pseudoequatorial position, whereas the anti-tert-butyl substituent is pseudo-axial; and I2, where this relationship is reversed (Scheme 4). Analysis of these two conformations suggests that steric repulsions between the axial syn-substituent and the methylene group in cyclopropane makes conformation $\mathbf{I} 2$ thermodynamically disfavored compared to I1. This hypothesis was also supported by a single crystal X-ray analysis of (L1) $\mathrm{PdCl}_{2}$ complex (Figure 4). The resolved crystal structure clearly shows that the syn-(C14) and anti-substituent (C18) at phosphorus

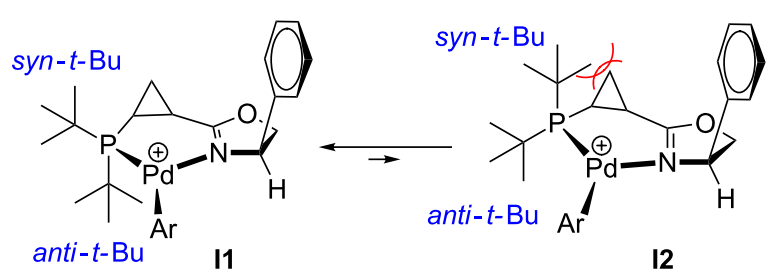

Scheme 4: Conformational equilibrium in cationic arylpalladium(II) complexes with chiral ligand L1.
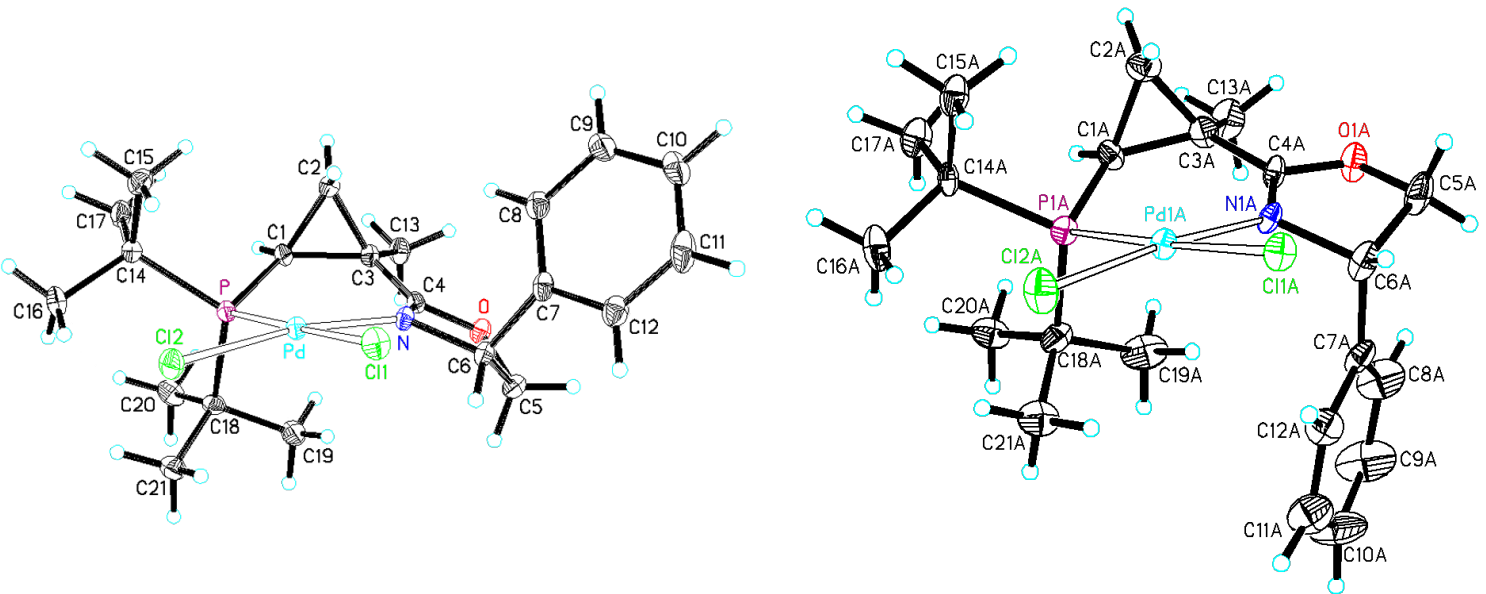

Figure 4: X-ray structures of complexes (L1) $\mathrm{PdCl}_{2}$ (left) and (L4) $\mathrm{PdCl}_{2}$ (right). These structures were originally communicated in [64]. 
adopt a pseudo-equatorial and a pseudo-axial position, respectively. It would be reasonable to assume that the strained and rigid cyclopropyl backbone renders the six-membered palladacycle particularly inflexible, thus significantly suppressing conformational fluctuations throughout the catalytic cycle. Furthermore, coordination of the soft $\pi$-ligand dihydrofuran should take place predominantly trans to a soft phosphorus atom [7072] (Scheme 5). In this case, the re-face approach (I4) is encumbered by a large pseudo-axial tert-butyl group, while the $s i$-face approach (I3) is also somewhat hindered by a pseudoaxial syn-phenyl substituent in dihydrooxazole ring. As a result, the $(R)$-enantiomer of the product was predominantly formed, albeit with moderate enantioselectivity. Analogously, in the intermediate $\mathbf{I 5}$ derived from chiral ligand $\mathbf{L 2}$, the less bulky pseudo-axial phenyl substituent at phosphorus blocks the $r e$-face approach even less efficiently, which ultimately results in a further decrease of enantioselectivity (Scheme 5).

The reversal of enantioselectivity observed in the reaction carried out in the presence of $\mathbf{L 3}$ was explained in a similar fashion (Table 2, entries 5 and 6, Scheme 6). Thus, a bulky tertbutyl group in the dihydrooxazole ring creates the increased
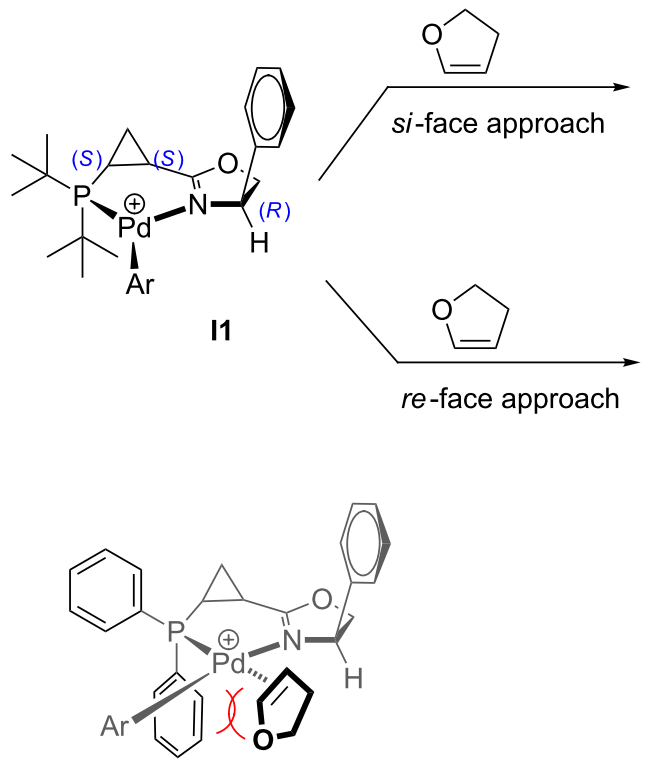

15

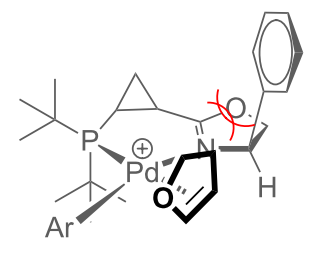

13

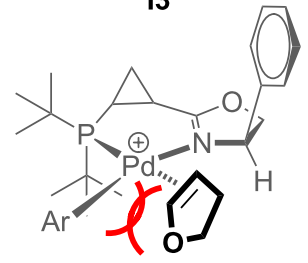

14

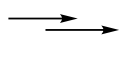

$\operatorname{Ar}_{0}^{(R)}$

(R)-3

major

$\operatorname{Ar}^{(S)} \backslash \overline{0}$

(S)-3

minor

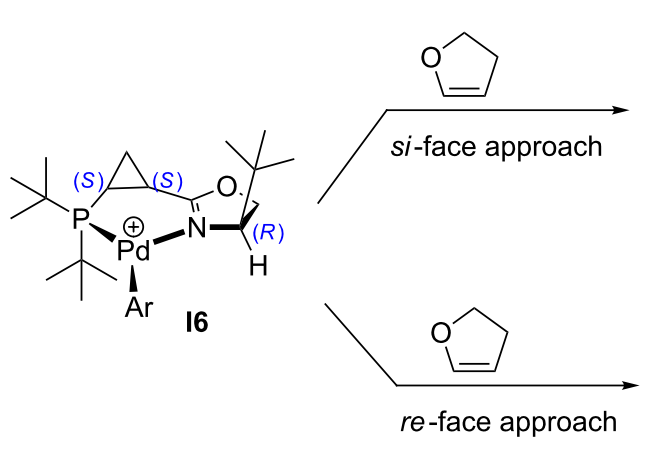

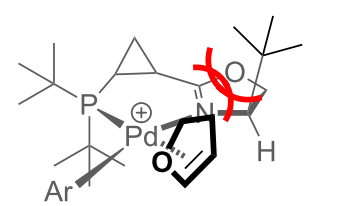

17

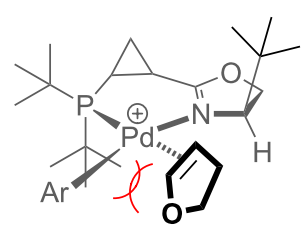

18

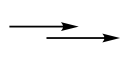<smiles>[Te][Te]C1[14CH]=CCO1</smiles>

(R)-3

minor<smiles>[Te][C]1C=CCO1</smiles>

$(S)-3$ major 
steric hindrance, which does not allow for the $s i$-face approach resulting in the reaction proceeding predominantly from the re-face, providing the (S)-enantiomer of $\mathbf{3}$ (Scheme 6). The fact that in both intermediates $\mathbf{I 7}$ and $\mathbf{I 8}$ dihydrofuran experiences certain impediment on approach to palladium may also be responsible for the observed decrease in the reaction rate.

Based on this analysis, we rationalized that the "wrong" relative configuration of the stereogenic centers in ligands $\mathbf{L 1}, \mathbf{L 2}$ and $\mathbf{L} \mathbf{3}$ could be responsible for the observed marginal enantioselectivity of the corresponding catalytic systems. We envisioned that inverting the absolute configuration of the asymmetric center at $\mathrm{C} 4$ in the dihydrooxazole ring might potentially help to improve the enantioselectivity of the arylation reaction. Indeed, it is reasonable to propose that the inversion of the stereogenic center in the dihydrooxazole ring should not significantly affect the thermodynamic equilibrium of the corresponding palladacycle conformations I9 and $\mathbf{I 1 0}$ (Scheme 7), as compared to I1 and $\mathbf{I 2}$ (Scheme 4). Thus, the cationic palladacycle with $(S, S, S)$-ligand $\mathbf{L} \mathbf{4}$ would still predominantly adopt conformation $\mathbf{I 9}$ to avoid the unfavorable steric interaction between the pseudo-axial syn-tert-butyl group and the methylene group of the cyclopropane (Scheme 7). Accordingly, a synergistic steric effect of both the axial $\mathrm{P}-t$-Bu group and a bulky substituent at $\mathrm{C} 4$ in dihydrooxazolyl moiety observed in the alternative $(S, S, S)$-configuration of the ligand would now provide efficient blocking of the both bottom quadrants thereby completely averting the re-face attack (I12, Scheme 8 ). On the other hand, the $s i$-face attack should become more favorable after the removal of a bulky group obstructing the top right quadrant (I11, Scheme 8 vs I3, Scheme 5). Ultimately, if the above assumptions are correct, this change should result in enhanced enantioselectivity of the asymmetric arylation in the presence of ligand $\mathbf{L} 4$ in favor of the $(R)$-enantiomer of the product 3 .

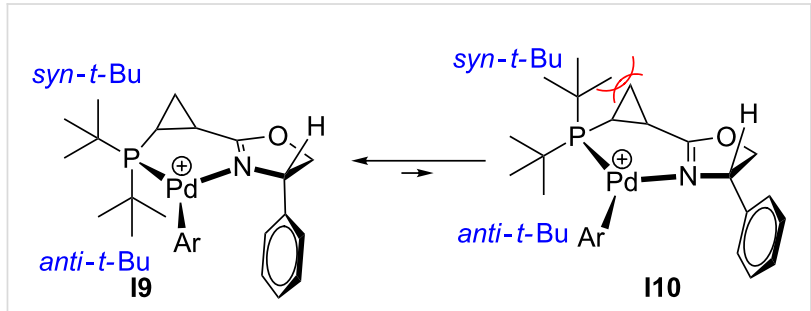

Scheme 7: Conformational equilibrium in cationic arylpalladium(II) complexes with chiral ligand L4.

With this idea in mind, we prepared a new series of ligands with the $(S, S, S)$-absolute configuration using the synthetic approach described above (Scheme 3), starting from acid chloride $(S)$-16 and $(S)$-phenylglycinol. Additional diversification of the ligand structure was achieved by varying the chlorophosphine source. Thus, employment of di-tert-butylchlorophosphine, chlorodicyclohexylphosphine, and chlorodiphenylphosphine at the last step of the sequence provided ligands L4, L5, and L6, respectively (Figure 3). Crystallographic data obtained for the (L4) $\mathrm{PdCl}_{2}$ complex (Figure 4) completely confirmed the preference of conformation I9 vs I10 (Scheme 7). It should be pointed out, that the resolved crystal structure of $(\mathbf{L 4}) \mathrm{PdCl}_{2}$ complex shows four sets of crystallographically independent molecules. However, all of them have nearly identical palladacycle conformations with the molecule shown in Figure 4 [64]. An overlay of X-ray structures obtained for (L1) $\mathrm{PdCl}_{2}$ and (L4) $\mathrm{PdCl}_{2}$ complexes demonstrated that all atoms of the palladacycle, cyclopropyl ring, and both tert-butyl substituents can be almost perfectly superimposed, which for both ligand configurations, confirms the strong preference of a conformation in which the syn-tert-Bu substituent $(\mathrm{C} 14)$ and the anti-tert-Bu substituent (C18) at phosphorus assume pseudoequatorial and pseudo-axial positions, respectively. Remarkably, X-ray analysis has also demonstrated that the phenyl substituent at $\mathrm{C} 4$ of dihydrooxazole ring adopts a pseudo-axial position thereby completely blocking any potential re-face attack (Scheme 8).

Ligands L4, L5, and $\mathbf{L 6}$ once obtained were tested in the asymmetric arylation of dihydrofuran 1 (Table 3). Gratifyingly, right along with our expectations, the entire series of $(S, S, S)$-ligands L4-L6 not only provided a significant improvement in enantioselectivity, but also helped to suppress the unwanted isomerization of $\mathbf{3}$ into $\mathbf{4}$, as compared to the diastereomeric ligand series (L1-L3, Table 2). Remarkably, changing the absolute configuration of the stereocenter in the dihydrooxazole ring did not cause the change of the absolute configuration of the product. This is in contrast to the reactions performed using most known PHOX ligands, in which configuration of the oxazoline moiety usually determines the stereochemical outcome of the reaction (however, in the reactions using PHOX ligands bearing a very bulky planar or axially chiral backbone, the enantiomeric outcome is controlled by the absolute configuration of the backbone rather than that of the oxazoline ring; for discussion, see [15]). Thus, employment of $\mathbf{L} \mathbf{4}$ and $\mathbf{L 5}$ afforded dihydrofuran $(R)-3$ with very high enantioselectivity regardless of the base used (Table 3, entries 1-6); however, the reactions proceeded more sluggishly in the presence of Hünig's base (Table 3, entries 2 and 5). Employment of proton sponge helped boost the reaction rate in the arylation catalyzed by both $\mathbf{L} 4$ and $\mathbf{L 5}$ (Table 3, entries 3 and 6). Yet, significant isomerization of $\mathbf{3}$ into 4 was observed with this base when the reaction catalyzed by $\mathbf{P d} / \mathbf{L} 4$ complex was allowed to run for an additional $20 \mathrm{~h}$ (Table 3, note c). Employment of the diphenylphosphanyl ligand L6 provided lower enantioselectivity (Table 3, entries 7 

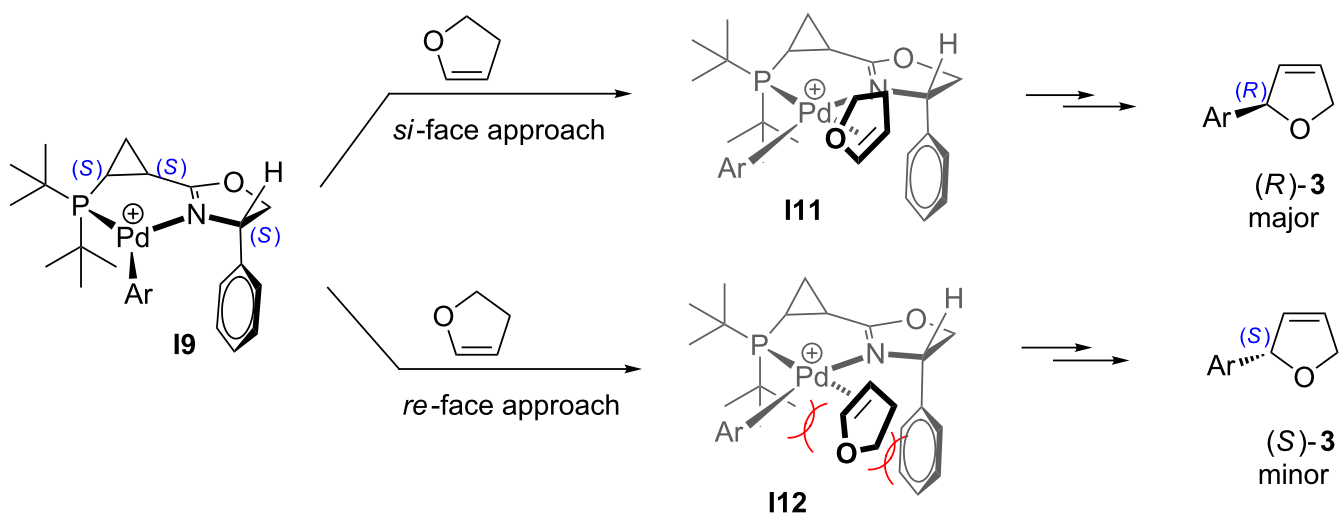

Scheme 8: For discussion on asymmetric induction imparted by chiral ligands L4 (originally published in [64]).

Table 3: Screening of L4-L6 in the asymmetric Heck arylation reaction.

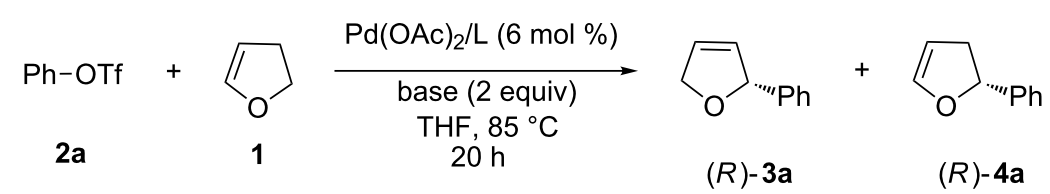

\begin{tabular}{|c|c|c|c|c|c|}
\hline Entry & Ligand & Base & $3 a: 4 a$ & ee $(3 a), \%$ & Conv, $\%^{a}$ \\
\hline 1 & L4 & $\mathrm{EtN}(\mathrm{iPr})_{2}$ & $>50: 1$ & 98 & 53 \\
\hline 2 & L4 & $\mathrm{EtN}(\mathrm{iPr})_{2}$ & $16: 1$ & 98 & $97^{b}$ \\
\hline 3 & L4 & proton sponge & $>50: 1^{c}$ & 98 & 74 \\
\hline 4 & L5 & $\mathrm{EtN}(\mathrm{iPr})_{2}$ & $>50: 1$ & 94 & 71 \\
\hline 5 & L5 & $\mathrm{EtN}(\mathrm{iPr})_{2}$ & $40: 1$ & 94 & $90^{b}$ \\
\hline 6 & L5 & proton sponge & $29: 1$ & 95 & 99 \\
\hline 7 & L6 & $\mathrm{EtN}(\mathrm{iPr})_{2}$ & $16: 1$ & 88 & 76 \\
\hline 8 & L6 & proton sponge & $>50: 1$ & 86 & 83 \\
\hline
\end{tabular}

${ }^{a}$ Conversions by GC. ${ }^{b}$ Conversion after 2 days at $85^{\circ} \mathrm{C}$. ${ }^{c}$ When the reaction was allowed to stir for an additional $20 \mathrm{~h}$, the product ratio changed to $2: 1$. The enantioselectivities of products $(R)-3 \mathbf{a}$ and $(R)-4 \mathbf{a}$ in this case were found to be $98 \%$ and $97 \%$, respectively.

and 8), which can be attributed to decreased steric demands created by phenyl groups at phosphorus as compared to the tertbutyl (L4) and cyclohexyl (L5) substituents.

The different tendencies of $\mathbf{P d} / \mathbf{L} \mathbf{1}$ and $\mathbf{P d} / \mathbf{L} \mathbf{4}$ catalyst systems to promote isomerization of product $\mathbf{3}$ into $\mathbf{4}$ can be rationalized as follows. As discussed above (Scheme 2), the isomerization process involves reversible hydropalladation of the double bond of product 3. The migration of the double bond can be realized only when hydropalladation of $\mathbf{3}$ occurs with addition of palladium to $\mathrm{C} 4$ (Scheme 9, path A), whereas the opposite regioselectivity of hydropalladation would ultimately lead, after the subsequent $\beta$-hydride elimination, back to compound $\mathbf{3}$ (Scheme 9, path B). The diastereoselectivity of the hydropalladation of $\mathbf{3}$ by $\mathrm{Pd} / \mathbf{L} \mathbf{1}$ hydride species $\mathbf{I 1 3}$ is controlled as shown in Scheme 10. Thus, it seems impossible to realize the $s i$-face approach of palladium hydride species I13 to the double bond of 3 due to severe steric hindrance between the di(tertbutyl)phospanyl group of the ligand and the aryl substituent in $\mathbf{3}$ on one side, and between the phenyl substituent in dihydrooxazole ring and C5-methylene of dihydrofuran 3 on the other (I15, Scheme 10). However, the absence of any significant steric interference upon alternative $r e$-face approach makes this alternative mechanistic channel available for isomerization (I14, Scheme 10).

Two potential pathways for hydropalladation of $\mathbf{3}$ by the diastereomeric $\mathbf{P d} / \mathbf{L} 4$ hydride species $\mathbf{I 1 6}$ are shown in Scheme 11. In conjunction with L1-derived complex I15 (Scheme 10), complex I18 produced via the $s i$-face approach 

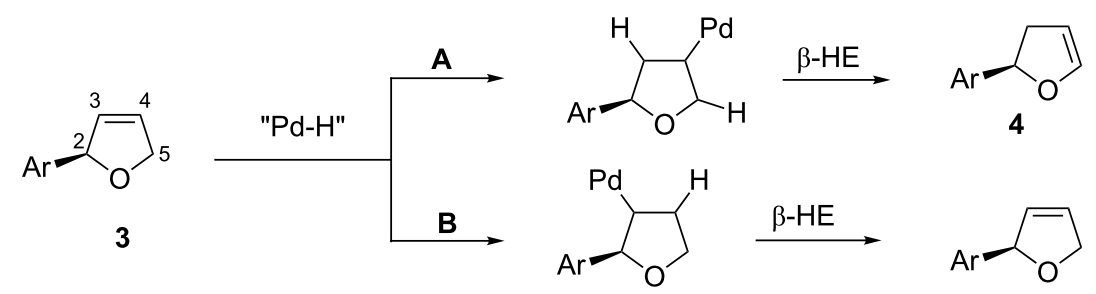

3

Scheme 9: Mechanism of migration of $C=C$ double bond leading to isomerization of product 3 into product 4.
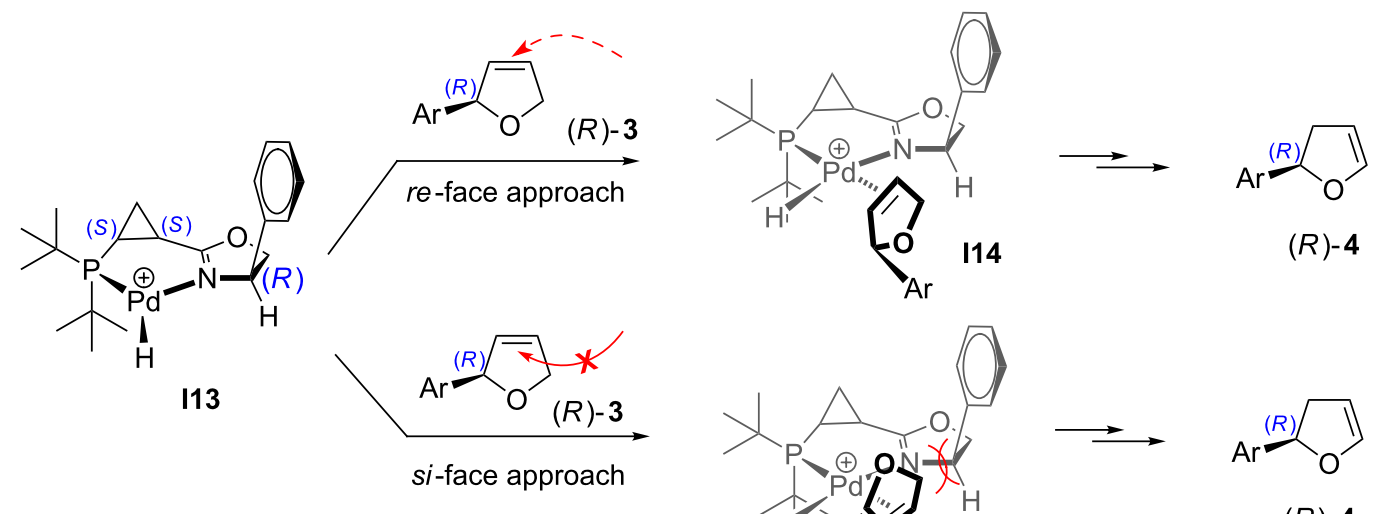

$(R)-4$
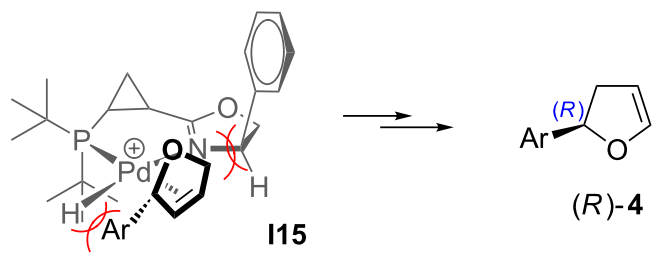

$(R)-4$

15

Scheme 10: For discussion on isomerization $\mathbf{3} \rightarrow \mathbf{4}$ imparted by Pd/L1 complex (originally published in [64])

should be highly disfavored (Scheme 11). In this case, however, an alternative complex $\mathbf{I 1 7}$ resulting from the re-face attack should also experience steric repulsion between the C5-methylene of dihydrofuran 3 and a pseudo-equatorial phenyl substituent in dihydrooxazole ring (Scheme 11). Accordingly, complex I17 should be much more unfavorable compared to L1-derived complex I14, where such interaction does not occur (Scheme 10). As a result, both mechanistic channels for isomer- ization of compound 3 into 4 should be suppressed in this case. It should be mentioned, however, that electronic density at the phosphine moiety of the ligand also notably affects the propensity of the corresponding catalyst to promote the isomerization. Thus, our experiments indicate that in the series of di(tertbutyl)-, dicyclohexyl-, and diphenylphosphanyl-containing ligands $(\mathbf{L} \mathbf{4} \rightarrow \mathbf{L 6}$ ), the former has the highest tendency to induce isomerization while the latter has the lowest (Table 3). A

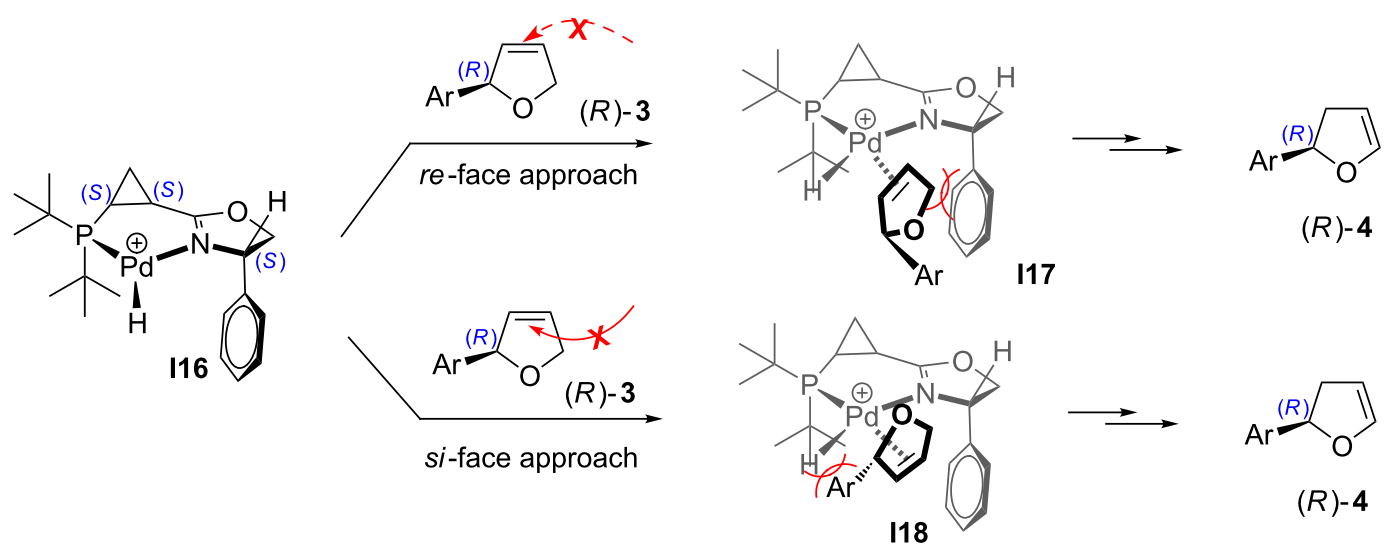

Scheme 11: For discussion on isomerization $\mathbf{3} \rightarrow \mathbf{4}$ imparted by Pd/L4 complex (originally published in [64]). 
similar electronic effect was previously observed in the asymmetric Heck arylation in the presence of diphosphine-oxazoline ferrocenyl ligands [56].

Next, the most efficient ligands $\mathbf{L} \mathbf{4}$ and $\mathbf{L 5}$ were tested in the asymmetric arylation of dihydrofuran $\mathbf{1}$ against various aryl triflates (Table 4). It was found that all reactions catalyzed by $\mathrm{Pd} / \mathbf{L} 4$ provided excellent enantioselectivities (98-99\%) regardless of the nature of the aryl triflate (Table 4, entries 1-5). However, the reactions carried out in the presence of $\mathbf{L 4} /$ Hünig's base combination proceeded much more sluggishly; as a result, the selectivity toward formation of $\mathbf{3}$ was slightly lower in these cases. Reactions performed in the presence of $\mathrm{Pd} / \mathbf{L 5}$ catalyst and proton sponge proceeded much faster, albeit providing somewhat lower ee's (Table 4, entries 6-10). In contrast to the $\mathrm{Pd} / \mathbf{L} 4$-catalyzed reactions, enantioselectivities in this case varied slightly depending on the aryl triflate used, with the highest value obtained from 1-naphthyl triflate $(96 \%$, Table 4, entry 9) and the lowest from 2-naphthyl triflate (87\%, Table 4, entry 10). Interestingly, the electronic nature of the aryl triflate had a pronounced effect on the reaction rate, which is best seen in the $\mathrm{Pd} / \mathbf{L} 5$ series of catalyzed reactions. Thus, electron-rich aryl triflates (Table 4, entries 6, 7, and 9) reacted much faster than the electron-poor analog $\mathbf{2 d}$ (Table 4, entry 8). Furthermore, a remarkable difference between the reactivity of 1- and 2-naphthyl triflates was also observed, suggesting the reaction is also sensitive to sterics (Table 4, entries 9 and 10).

We also tested all new ligands $\mathbf{L 1}-\mathbf{L 6}$ in the asymmetric Heck arylation of cyclopentene (Table 5). Initial experiments

Table 4: Asymmetric arylation of dihydrofuran with aryl tiflates

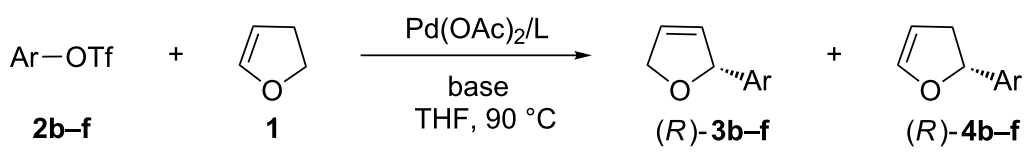

\begin{tabular}{|c|c|c|c|c|c|c|c|}
\hline Entry & Aryl & & Ligand/Base & Time, $\mathrm{h}$ & $3: 4$ & ee $(3), \%$ & Conv, $\%^{a}$ \\
\hline 1 & $p-\mathrm{Me}-\mathrm{C}_{6} \mathrm{H}_{4}$ & $2 b$ & L4/Hünig's base & 48 & $16: 1$ & 99 & 96 \\
\hline 2 & $p-\mathrm{MeO}-\mathrm{C}_{6} \mathrm{H}_{4}$ & $2 c$ & L4/Hünig's base & 20 & $17: 1$ & 98 & 98 \\
\hline 3 & $p-\mathrm{CF}_{3}-\mathrm{C}_{6} \mathrm{H}_{4}$ & $2 d$ & L4/Hünig's base & 48 & $>50: 1$ & 98 & 58 \\
\hline 4 & 1-Nphth & $2 e$ & L4/Hünig's base & 48 & 18:1 & 98 & $70^{b}$ \\
\hline 5 & 2-Nphth & $2 f$ & L4/Hünig's base & 20 & $>50: 1$ & 98 & $32^{b}$ \\
\hline 6 & $p-\mathrm{Me}-\mathrm{C}_{6} \mathrm{H}_{4}$ & $2 b$ & L5/proton sponge & 6 & $39: 1$ & 95 & 93 \\
\hline 7 & $p-\mathrm{MeO}-\mathrm{C}_{6} \mathrm{H}_{4}$ & $2 c$ & L5/proton sponge & 6 & $35: 1$ & 92 & 99 \\
\hline 8 & $p-\mathrm{CF}_{3}-\mathrm{C}_{6} \mathrm{H}_{4}$ & $2 d$ & L5/proton sponge & 20 & $42: 1$ & 91 & 95 \\
\hline 9 & 1-Nphth & $2 e$ & L5/proton sponge & 6 & $31: 1$ & 96 & $94^{b}$ \\
\hline 10 & 2-Nphth & $2 f$ & L5/proton sponge & 20 & $17: 1$ & 87 & $100^{c}$ \\
\hline
\end{tabular}

${ }^{a}$ Conversion by GC. ${ }^{b}$ Formation of ca. $10 \%$ of naphthalene was observed. ${ }^{\mathrm{C}}$ Formation of ca. $20 \%$ of naphthalene was observed.

Table 5: Evaluation of Ligands L1-L6 in the intermolecular asymmetric Heck reaction of phenyl triflate (2a) with cyclopentene (19).

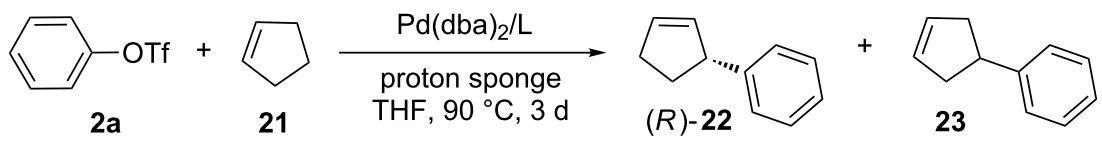

\begin{tabular}{llllll}
\hline Entry & Ligand & $\mathbf{2 2 : 2 3}$ & ee (22), \% & Conv, \%a \\
\hline 1 & L1 & $12: 1$ & 81 & 99 & 85 \\
2 & L2 & $15: 1$ & 86 & 95 & 80 \\
3 & L3 & $13: 1$ & 82 & 15 & ND \\
4 & L4 & $27: 1$ & 92 & 32 & ND \\
5 & L5 & $44: 1$ & 89 & 96 & 80 \\
6 & L6 & $40: 1$ & 80 & 60 & ND \\
\hline
\end{tabular}

aConversion by GC. ' Isolated yields, obtained by standard aqueous work-up of the reaction mixture, followed by fractionation. 
conducted under the conditions optimized for arylation of dihydrofuran 1 provided no reaction with cyclopentene 21. Additional optimization revealed that reasonable reaction rates can be achieved only in the presence of $\mathrm{Pd}(\mathrm{dba})_{2}$ catalyst and proton sponge. It should be mentioned that employment of $\mathrm{Pd}_{2}(\mathrm{dba})_{3} \cdot \mathrm{CHCl}_{3}$ catalyst in place of $\mathrm{Pd}(\mathrm{dba})_{2}$ provided no reaction. Generally, the enantioselectivities obtained in this transformation (Table 5) were somewhat lower than those obtained in the arylation of dihydrofuran (Table 2 and Table 3) for all ligands tested except $\mathbf{L} 4$. Notably, similarly to the arylation of dihydrofuran (Table 2 and Table 3), the isomerization rates $(\mathbf{2 2} \rightarrow \mathbf{2 3})$ in this transformation were significantly lower in the reactions carried out in the presence of ligands with the $(S, S, S)$ absolute configuration (L4-L6, Table 5, entries 4-6), as compared to the ligands in the diastereomeric series $(\mathbf{L 1}-\mathbf{L 3}$, Table 5, entries 1-3).

\section{Conclusion}

In conclusion, a series of novel PHOX ligands featuring a chiral cyclopropyl backbone have been synthesized and examined in the intermolecular asymmetric Heck arylation of cyclic olefins. By lowering degrees of freedom in the catalyst structure through the introduction of additional conformation constrains, we have created a model catalytic system with predictable, tuneable and easily adjustable properties. Structure-activity relationship studies allowed for identifying the key topological and stereochemical features of the ligands, responsible for achieving high enantioselectivity and for suppressing product isomerization. This has resulted in the development of efficient catalytic systems demonstrating excellent enantioselectivities in the asymmetric arylation of dihydrofuran with various aryl triflates. It was also shown that the product isomerization in the presence of these ligands has a different nature from that reported previously using chiral diphosphine ligands. Furthermore, a number of factors were shown to affect the isomerization rate including the absolute configuration of the ligand, its electronic properties, and the base employed.

\section{Supporting Information}

\section{Supporting Information File 1}

Detailed experimental procedures of chiral ligands L2, L5, and L6.

[http://www.beilstein-journals.org/bjoc/content/ supplementary/1860-5397-10-158-S1.pdf]

\section{Acknowledgements}

Financial support from the University of Kansas and the National Science Foundation (EEC-0310689) is gratefully acknowledged. We are grateful to International Collaboration
Program, supported by the Ministry of Education and Science of the Russian Federation and the Ural Federal University. We also thank National Science Foundation (grant CHE-0079282) for funds to purchase the X-ray instrument and Dr. V. W. Day (X-ray Crystallography Laboratory, University of Kansas) for his assistance with X-ray crystallography.

\section{References}

1. Sato, Y.; Sodeoka, M.; Shibasaki, M. J. Org. Chem. 1989, 54, 4738-4739. doi:10.1021/jo00281a007

2. Carpenter, N. E.; Kucera, D. J.; Overman, L. E. J. Org. Chem. 1989, 54, 5846-5848. doi:10.1021/jo00286a009

3. Oestreich, M. Eur. J. Org. Chem. 2005, 783-792. doi:10.1002/ejoc.200400711

4. Guiry, P. J.; Kiely, D. Curr. Org. Chem. 2004, 8, 781-794. doi: $10.2174 / 1385272043370528$

5. Iserloh, U.; Curran, D. P. Chemtracts 1999, 12, 289-296.

6. Dounay, A. B.; Overman, L. E. Chem. Rev. 2003, 103, 2945-2964. doi:10.1021/cr020039h

7. Guiry, P. J.; Hennessy, A. J.; Cahill, J. P. Top. Catal. 1997, 4, 311-326. doi:10.1023/A:1019121113063

8. Steven, A.; Overman, L. E. Angew. Chem., Int. Ed. 2007, 46, 5488-5508. doi:10.1002/anie.200700612

9. Liu, S.; Zhou, J. Chem. Commun. 2013, 49, 11758-11760. doi:10.1039/c3cc47551d

10. Hu, J.; Lu, Y.; Li, Y.; Zhou, J. Chem. Commun. 2013, 49, 9425-9427. doi:10.1039/c3cc45233f

11. Mei, T.-S.; Werner, E. W.; Burckle, A. J.; Sigman, M. S. J. Am. Chem. Soc. 2013, 135, 6830-6833. doi:10.1021/ja402916z

12. Yang, Z.; Zhou, J. J. Am. Chem. Soc. 2012, 134, 11833-11835. doi:10.1021/ja304099j

13. Yasui, Y.; Takeda, H.; Takemoto, Y. Chem. Pharm. Bull. 2008, 56, 1567-1574. doi:10.1248/cpb.56.1567

14. Dounay, A. B.; Humphreys, P. G.; Overman, L. E.; Wrobleski, A. D J. Am. Chem. Soc. 2008, 130, 5368-5377. doi:10.1021/ja800163v

15. Shibasaki, M.; Vogl, E. M.; Ohshima, T. Adv. Synth. Catal. 2004, 346, 1533-1552. doi:10.1002/adsc.200404203

16. Ozawa, F.; Kubo, A.; Hayashi, T. J. Am. Chem. Soc. 1991, 113, 1417-1419. doi:10.1021/ja00004a056

17. Ozawa, F.; Kobatake, Y.; Hayashi, T. Tetrahedron Lett. 1993, 34, 2505-2508. doi:10.1016/S0040-4039(00)60453-7

18. Ozawa, F.; Hayashi, T. J. Organomet. Chem. 1992, 428, 267-277. doi:10.1016/0022-328X(92)83236-B

19. Hopkins, J. M.; Gorobets, E.; Wheatley, B. M. M.; Pravez, M.; Keay, B. A. Synlett 2006, 3120-3124. doi:10.1055/s-2006-950404

20. Wöste, T. H.; Oestreich, M. Chem.-Eur. J. 2011, 17, 11914-11918. doi:10.1002/chem.201101695

21. Shimizu, H.; Nagasaki, I.; Saito, T. Tetrahedron 2005, 61, 5405-5432. doi:10.1016/j.tet.2005.03.022

22. Selvakumar, K.; Valentini, M.; Pregosin, P. S.; Albinati, A.; Eisenträger, F. Organometallics 2000, 19, 1299-1307. doi:10.1021/om990892f

23. Tschoerner, M.; Pregosin, P. S.; Albinati, A. Organometallics 1999, 18, 670-678. doi:10.1021/om9807831

24. Trabesinger, G.; Albinati, A.; Feiken, N.; Kunz, R. W.; Pregosin, P. S.; Tschoerner, M. J. Am. Chem. Soc. 1997, 119, 6315-6323. doi:10.1021/ja964406g 
25. Siutkowski, M.; Mercier, F.; Ricard, L.; Mathey, F. Organometallics 2006, 25, 2585-2589. doi:10.1021/om060118+

26. Gibson, S. E.; Ibrahim, H.; Pasquier, C.; Swamy, V. M. Tetrahedron: Asymmetry 2003, 14, 1455-1458. doi:10.1016/S0957-4166(03)00204-0

27. Gibson, S. E.; Ibrahim, H.; Pasquier, C.; Swamy, V. M. Tetrahedron: Asymmetry 2004, 15, 465-473. doi:10.1016/j.tetasy.2003.11.014

28. Tietze, L. F.; Thede, K.; Schimpf, R.; Sannicolò, F. Chem. Commun. 2000, 583-584. doi:10.1039/a909689b

29. Benincori, T.; Piccolo, O.; Rizzo, S.; Sannicolò, F. J. Org. Chem. 2000 65, 8340-8347. doi:10.1021/jo001207d

30. Tietze, L. F.; Thede, K. Chem. Commun. 1999, 1811-1812. doi:10.1039/a905309c

31. Tietze, L. F.; Thede, K. Synlett 2000, 1470-1472. doi:10.1055/s-2000-7628

32. Gorobets, E.; Sun, G.-R.; Wheatley, B. M. M.; Parvez, M.; Keay, B. A. Tetrahedron Lett. 2004, 45, 3597-3601. doi:10.1016/j.tetlet.2004.03.073

33. Andersen, N. G.; McDonald, R.; Keay, B. A. Tetrahedron: Asymmetry 2001, 12, 263-269. doi:10.1016/S0957-4166(01)00035-0

34. Andersen, N. G.; Parvez, M.; Keay, B. A. Org. Lett. 2000, 2, 2817-2820. doi:10.1021/ol006238+

35. Au-Yeung, T. T.-L.; Chan, A. S. C. Coord. Chem. Rev. 2004, 248, 2151-2164. doi:10.1016/j.ccr.2004.08.026

36. Mellah, M.; Voituriez, A.; Schulz, E. Chem. Rev. 2007, 107, 5133-5209. doi:10.1021/cr068440h

37. Kang, J.; Lee, J. H.; Im, K. S. J. Mol. Catal. A 2003, 196, 55-63. doi:10.1016/S1381-1169(02)00634-9

38. Dai, W.-M.; Yeung, K. K. Y.; Wang, Y. Tetrahedron 2004, 60, 4425-4430. doi:10.1016/j.tet.2004.02.062

39. Dodd, D. W.; Toews, H. E.; Carneiro, F. d. S.; Jennings, M. C.; Jones, N. D. Inorg. Chim. Acta 2006, 359, 2850-2858. doi:10.1016/j.ica.2005.11.025

40. Yoo, K. S.; Park, C. P.; Yoon, C. H.; Sakaguchi, S.; O'Neill, J.; Jung, K. W. Org. Lett. 2007, 9, 3933-3935. doi:10.1021/ol701584f

41. Kündig, E. P.; Meier, P. Helv. Chim. Acta 1999, 82, 1360-1370. doi:10.1002/(SICI)1522-2675(19990908)82:9<1360::AID-HLCA1360>3 .3.CO;2-M

42. Malkov, A. V.; Bella, M.; Stará, I. G.; Kočovský, P. Tetrahedron Lett. 2001, 42, 3045-3048. doi:10.1016/S0040-4039(01)00369-0

43. Fitzpatrick, M. O.; Muller-Bunz, H.; Guiry, P. J. Eur. J. Org. Chem. 2009, 1889-1895. doi:10.1002/ejoc.200800761

44. Henriksen, S. T.; Norrby, P.-O.; Kaukoranta, P.; Andersson, P. G. J. Am. Chem. Soc. 2008, 130, 10414-10421. doi:10.1021/ja802991y

45. Chelucci, G.; Orrù, G.; Pinna, G. A. Tetrahedron 2003, 59, 9471-9515. doi:10.1016/j.tet.2003.09.066

46. Liu, D.; Dai, Q.; Zhang, X. Tetrahedron 2005, 61, 6460-6471. doi:10.1016/j.tet.2005.03.111

47. Mata, Y.; Diéguez, M.; Pàmies, O.; Claver, C. Org. Lett. 2005, 7, 5597-5599. doi:10.1021/ol052176h

48. Mata, Y.; Pàmies, O.; Diéguez, M. Chem.-Eur. J. 2007, 13, 3296-3304. doi:10.1002/chem.200601714

49. Drury, W. J., III; Zimmerman, N.; Keenan, M.; Hayashi, M.; Kaiser, S.; Goddard, R.; Pfaltz, A. Angew. Chem., Int. Ed. 2004, 43, 70-74. doi:10.1002/anie.200352755

50. Kilroy, T. G.; Cozzi, P. G.; End, N.; Guiry, P. J. Synthesis 2004, 1879-1888. doi:10.1055/s-2004-829168
51. Hashimoto, Y.; Horie, Y.; Hayashi, M.; Saigo, K Tetrahedron: Asymmetry 2000, 11, 2205-2210. doi:10.1016/S0957-4166(00)00157-9

52. Gilbertson, S. R.; Xie, D.; Fu, Z. J. Org. Chem. 2001, 66, 7240-7246. doi:10.1021/jo0158231

53. Loiseleur, O.; Hayashi, M.; Schmees, N.; Pfaltz, A. Synthesis 1997, 1338-1345. doi:10.1055/s-1997-1341

54. Loiseleur, O.; Meier, P.; Pfaltz, A. Angew. Chem., Int. Ed. 1996, 35, 200-202. doi:10.1002/anie.199602001

55. Tu, T.; Deng, W.-P.; Hou, X.-L.; Dai, L.-X.; Dong, X.-C. Chem.-Eur. J. 2003, 9, 3073-3081. doi:10.1002/chem.200204450

56. Dai, L.-X.; Tu, T.; You, S.-L.; Deng, W.-P.; Hou, X.-L. Acc. Chem. Res. 2003, 36, 659-667. doi:10.1021/ar020153m

57. Hennessy, A. J.; Conolly, D. J.; Malone, Y. M.; Guiry, P. J. Tetrahedron Lett. 2000, 41, 7757-7761. doi:10.1016/S0040-4039(00)01325-3

58. Kilroy, T. G.; Hennessy, A. J.; Conolly, D. J.; Malone, Y. M.; Farrell, A.; Guiry, P. J. J. Mol. Catal. A 2003, 196, 65-81. doi:10.1016/S1381-1169(02)00635-0

59. Gilbertson, S. R.; Fu, Z. Org. Lett. 2001, 3, 161-164. doi:10.1021/ol006747b

60. Molander, G. A.; Burke, J. P.; Carrol, P. J. J. Org. Chem. 2004, 69, 8062-8069. doi:10.1021/jo048782s

61. Aviron-Violet, P.; Colleuille, Y.; Varagnat, J. J. Mol. Catal. 1979, 5, 41-50. doi:10.1016/0304-5102(79)80080-2

62. Okada, Y.; Minami, T.; Yamamoto, T.; Ichikawa, J. Chem. Lett. 1992 21, 547-550. doi:10.1246/cl.1992.547

63. Khlebnikov, A. F.; Kozhushkov, S. I.; Yufit, D. S.; Schill, H.; Reggelin, M.; Spohr, V.; de Meijere, A. Eur. J. Org. Chem. 2012, 1530-1545. doi:10.1002/ejoc.201101715

64. Rubina, M.; Sherrill, W. M.; Rubin, M. Organometallics 2008, 27, 6393-6395. doi:10.1021/om801051d

65. Baird, M. S.; Licence, P.; Tverezovsky, V. V.; Bolesov, I. G.; Clegg, W. Tetrahedron 1999, 55, 2773-2784. doi:10.1016/S0040-4020(99)00048-4

66. Mawo, R. Y.; Johnson, D. M.; Wood, J. L.; Smoliakova, I. P. J. Organomet. Chem. 2008, 693, 33-45. doi:10.1016/j.jorganchem.2007.10.011

67. Lee, H. M.; Lu, C. Y.; Chen, C. Y.; Chen, W. L.; Lin, H. C.; Chiu, P. L.; Cheng, P. Y. Tetrahedron 2004, 60, 5807-5825. doi:10.1016/j.tet.2004.04.070

68. Benito, M.; López, C.; Morvan, X. Polyhedron 1999, 18, 2583-2595. doi:10.1016/S0277-5387(99)00163-1

69. Slawin, A. M. Z.; Smith, M. B.; Woollins, J. D. Polyhedron 1998, 17, 4465-4473. doi:10.1016/S0277-5387(98)00253-8

70. Lee, S.; Lim, C. W.; Song, C. E.; Kim, K. M.; Jun, C. H. J. Org. Chem. 1999, 64, 4445-4451. doi:10.1021/jo990126i

71. Togni, A.; Burckhardt, U.; Gramlich, V.; Pregosin, P. S.; Salzmann, R. J. Am. Chem. Soc. 1996, 118, 1031-1037. doi:10.1021/ja953031g

72. von Matt, P.; Pfaltz, A. Angew. Chem., Int. Ed. Engl. 1993, 32, 566-568. doi:10.1002/anie.199305661 


\section{License and Terms}

This is an Open Access article under the terms of the Creative Commons Attribution License

(http://creativecommons.org/licenses/by/2.0), which permits unrestricted use, distribution, and reproduction in any medium, provided the original work is properly cited.

The license is subject to the Beilstein Journal of Organic Chemistry terms and conditions:

(http://www.beilstein-journals.org/bjoc)

The definitive version of this article is the electronic one which can be found at:

doi:10.3762/bjoc. 10.158 